ARAÚJO, R.P. et al. Sistema silvipastoril como alternativa de uso da terra. PUBVET, Londrina, V. 5, N. 38, Ed. 185, Art. 1245, 2011.

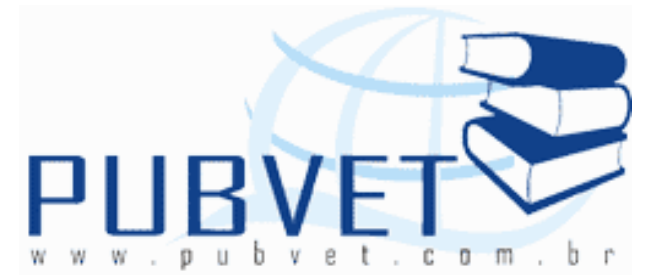

PUBVET, Publicações em Medicina Veterinária e Zootecnia.

\title{
Sistema silvipastoril como alternativa de uso da terra
}

Raphael Pavesi Araújo1, João Carlos de Carvalho Almeida², Bruno Borges Deminicis $^{3}$, Saulo Alberto do Carmo Araújo ${ }^{4}$, Everton Teixeira Ribeiro ${ }^{5}$, Mariá Moraes Amorim ${ }^{6}$, Patricia do Rosario Rodrigues ${ }^{6}$

${ }^{1}$ Doutorando em Ciência Animal, Universidade Estadual do Norte Fluminense. Laboratório de Zootecnia e Nutrição Animal. Campos dos Goytacazes, RJ

${ }^{2}$ Professor Associado II, Universidade Federal Rural do Rio de Janeiro. Departamento de Nutrição Animal e Pastagens. Seropédica, RJ. Brasil.

${ }^{3}$ Professor Adjunto, Universidade Federal do Espírito Santo. Departamento de Zootecnia. Alegre, ES, Brasil.

${ }^{4}$ Professor Adjunto, Universidade Federal dos Vales do Jequitinhonha e Mucuri. Departamento de Zootecnia. Diamantina, MG, Brasil.

${ }^{5}$ Mestrando em Zootecnia, Universidade Federal Rural do Rio de Janeiro. Departamento de Nutrição Animal e Pastagens. Seropédica, RJ. Brasil. ${ }^{6}$ Graduanda em Zootecnia, Universidade Federal do Espírito Santo. Departamento de Zootecnia. Alegre, ES, Brasil.

\section{Resumo}

Atualmente duas grandes vertentes estão sendo amplamente difundidas, estas dizem respeito ao aumento da demanda mundial por alimentos em especial por proteína de origem animal e outra sobre a preservação ambiental, porem, estes apresentam um fator complicador que está relacionado à grande 
ARAÚJO, R.P. et al. Sistema silvipastoril como alternativa de uso da terra. PUBVET, Londrina, V. 5, N. 38, Ed. 185, Art. 1245, 2011.

demanda por madeira, fazendo com que haja um aumento do desmatamento ilegal, com substituição das áreas de mata por pastagem que irão servir de alimento para os animais. Diante deste cenário, surgiram os sistemas silvipastoris que é uma modalidade de sistema agroflorestal que se refere às técnicas de produção nas quais se integram os animais, as árvores e as pastagens numa mesma área. A utilização desses sistemas pode ser benéfica quando aplicados de maneira correta, no entanto sua forma de utilização foi durante anos feita de maneira equivocada, o que provocou uma diminuição da utilização destes sistemas. Com isso, esta revisão tem por objetivo caracterizar os componentes e fazer uma classificação dos sistemas silvipastoris para que este possa ter um melhor entendimento de sua utilização.

Palavras-chave: Brachiaria, sistema silvipastoril e agrofloresta.

\section{Silvipastoral system an alternative of soil use}

\section{Abstract}

Now two great slopes are being thoroughly spread, these concern the increase of the world demand for victuals especially for protein of animal origin and another about the environmental preservation, they put, these present a complication factor that is related to great demand for wood, doing with that there is an increase of the illegal deforestation, with substitution of the forest areas for pasture that will serve as food for the animals. Before this scenery, the silvipastoral systems that it is a modality of agroforestry system that refers to the production techniques in which become complete the animals, the trees and the pastures in a same area appeared. The use of those systems can be beneficial when applied in a correct way, however your use form was during years done in a mistaken way, what provoked a decrease of the use of these systems. With that, this revision has for objective to characterize the components and to do a classification of the silvipastoral systems so that this can have a better understanding of your use.

Keywords: Brachiaria, silvipastoral systems and agroforestry. 
ARAÚJO, R.P. et al. Sistema silvipastoril como alternativa de uso da terra. PUBVET, Londrina, V. 5, N. 38, Ed. 185, Art. 1245, 2011.

\section{INTRODUÇÃO}

O Brasil possui um grande território, por esse motivo e pelo fato de ter um clima extremamente favorável, vem despontando nas últimas décadas na produção de animais ruminantes. Entretanto, independente da espécie explorada, o sistema de produção predominante é caracterizado por animais a pasto com pequena ou nenhuma suplementação no período seco do ano. $O$ que justifica a extensa área de pastagem existente no país, além de um grande problema que tem sido documentado nos últimos anos, que é o nível de degradação em que se encontra a maior parte dessas áreas de pastagem. Isto se dá principalmente devido à falta de transferência de tecnologia gerada nas instituições de pesquisa, bem como a resistência dos produtores mais tradicionais em aceitá-las.

A degradação das pastagens é a principal "vilã" da pecuária atual, por causar vários problemas não só para a produção animal, mas também para o meio ambiente. Estudos feitos através de satélites, na Amazônia legal, estimam que 15 milhões de hectares de mata já foram derrubados para implantação de área de pastagens e que pelo menos a metade desta área já está degradada (Embrapa, 2005). Os prejuízos referentes à produção animal estão relacionados à baixa produção dessas pastagens o que resulta em uma menor capacidade de suporte, diminuindo assim drasticamente a quantidade de animais por fazenda ou a manutenção desses animais em um estado de deficiência nutricional quase permanente. Entretanto, o maior problema causado pela degradação das pastagens é devido aos seus inúmeros efeitos no meio ambiente, tais como: menor infiltração da água no solo, causada pela diminuição dos poros do solo em decorrência da baixa produção e decomposição de raízes o que formaria verdadeiros dutos e o continuo pisoteio dos animais aumentando a sua compactação. Em resposta a esses efeitos irá ocorrer um escorrimento superficial da água causando erosão devido ao carreamento de partículas de solo e nutriente determinando um aumento do empobrecimento do solo, além disso, esse material arrastado será depositado 
ARAÚJO, R.P. et al. Sistema silvipastoril como alternativa de uso da terra. PUBVET, Londrina, V. 5, N. 38, Ed. 185, Art. 1245, 2011.

nos rios e córregos o que causará o assoreamento dos mesmos promovendo inundações frequentes de áreas de várzea.

Com objetivo de amenizar e até mesmo eliminar todos esses problemas tem-se feito muitos estudos e várias técnicas já estão sendo desenvolvidas. Os Sistemas Agroflorestais vêm se destacando devido a gama de benefícios na ocasião de sua utilização, constituindo alternativas sustentáveis para aumentar os níveis de produção agrícola, animal e florestal. Estes são classificados de acordo com a natureza e arranjo de seus componentes, podendo ser assim denominados: silviagrícolas, aqueles constituídos de árvores e/ou de arbustos com culturas agrícolas; silvipastoris, cultivos de árvores e/ou de arbustos com pastagens e/ou animais; e agrossilvipastoris, cultivo de árvores e/ou arbustos com culturas agrícolas, pastagens e/ou animais de maneira simultânea ou seqüencial (Medrado, 2000).

O sistema silvipastoril pode ser descrito como modelos de uso da terra que se baseia na consorciação de espécies florestais com o cultivo de pastagens em uma mesma área de forma simultânea ou sequencial, podendo ser atribuídas a este sistema muitas vantagens, tais como a manutenção das pastagens sem que esta entre em estado de degradação, melhoria do conforto animal pela melhor distribuição de sombras na pastagem, aumento da produtividade animal, diminuição da necessidade de abertura de novas áreas de mata.

Tendo em vista estas considerações, objetivou-se com esta revisão abordar alguns aspectos da utilização do sistema silvipastoril.

\section{PASTAGENS NO BRASIL}

O Brasil possui cerca de 200 milhões de hectares de pastagens, e os sistemas de produção animal são, em sua maioria, baseados na exploração destas áreas. Estimativas admitem que 80 a $90 \%$ das áreas de pastagens no País são constituídas por espécies forrageiras, do gênero Brachiaria, principalmente $B$. decumbens e B. brizantha (Boddey et al., 2004). 
ARAÚJO, R.P. et al. Sistema silvipastoril como alternativa de uso da terra. PUBVET, Londrina, V. 5, N. 38, Ed. 185, Art. 1245, 2011.

O gênero Brachiaria representa um marco na pecuária nacional com a ocupação de grandes áreas do cerrado na região central do Brasil, bem como em áreas onde cultivares de Panicum maximum Jacq. apresentavam declínio na produtividade, pela baixa fertilidade natural do solo e por manejo inadequado. A utilização de espécies e/ou cultivares de Brachiaria foi viabilizado pelo conjunto de características desejáveis dessas forrageiras (Fagundes et al, 2006), porém as pastagens de Brachiaria foram formadas, em sua maioria, em solos de baixa fertilidade natural, e apesar de sua adaptação, isto contribuiu para o avanço do processo de degradação, poucos anos após o estabelecimento das pastagens (Boddey et al., 2004).

O manejo dessas pastagens e do pastejo, juntamente com a introdução e avaliação de novos cultivares de gramíneas e leguminosas, têm sido alvos prioritários da experimentação com plantas forrageiras tropicais no Brasil há muito tempo. Tradicionalmente, a grande maioria dos trabalhos de pesquisa, principalmente no que se refere ao manejo do pastejo, possuía um enfoque extremamente simplista do processo produtivo. Os resultados colhidos apresentam, invariavelmente, um caráter muito regional, dificultando a extrapolação para diferentes ecossistemas uma vez que na maioria das vezes não se fornecia informações que permitissem o entendimento e a compreensão das relações de causa e efeito determinantes das respostas de plantas e animais em pastagens, premissa básica para a elaboração e planejamento de práticas de manejo sustentáveis (Da Silva e Nascimento JR., 2006).

Um dos principais problemas de pastagens de gramíneas tropicais é a acentuada estacionalidade na produção de forragem, resultante da existência de duas estações climáticas bem definidas (chuvas e seca). Na época das chuvas, as condições climáticas são, geralmente, favoráveis ao crescimento das espécies forrageiras, enquanto que durante a seca, os fatores climáticos são adversos ao crescimento dessas espécies. Reduzida precipitação, baixa temperatura e condições adversas de luminosidade, são considerados os principais elementos limitantes para o crescimento e desenvolvimento de forrageiras no período de inverno (Paciullo et al., 2005). 
ARAÚJO, R.P. et al. Sistema silvipastoril como alternativa de uso da terra. PUBVET, Londrina, V. 5, N. 38, Ed. 185, Art. 1245, 2011.

Com isso, em uma expressiva área das pastagens existentes, sinais evidentes de degradação têm sido observados em poucos anos após sua formação (Alvim et al., 2002). Este processo de degradação se manifesta pela queda gradual e constante de produtividade das forrageiras devido a vários fatores, notadamente, baixa adaptabilidade do germoplasma forrageiro, baixa fertilidade dos solos, manejo deficiente das pastagens, o que culmina com a dominância total da área por plantas invasoras, mais adaptadas às condições ecológicas prevalescentes, tornando as medidas de manutenção, como limpeza e queima das pastagens, cada vez mais frequentes (Costa et al., 2006).

A degradação de pastagens têm sido uma constante nos países tropicais, cujo processo é favorecido pelas condições edafoclimáticas, aliadas ao manejo inadequado de animais e solos, à desinformação e à falta de recursos financeiros por parte dos produtores rurais. Este conjunto de fatores negativos, aliados à forma extrativista de utilização das pastagens, inviabiliza a continuidade da exploração, se não são tomadas medidas de recuperação (Spera et al., 1993).

Uma solução viável para se enfrentar esse problema é o estabelecimento de sistemas silvipastoris, que proporciona inúmeros benefícios ao sistema animal-solo-planta. Pois a árvore integrada ao sistema pode aumentar a produtividade e qualidade da forragem e ainda promover a sustentabilidade do sistema (Garcia et al., 2005).

Ainda, segundo Andrade et al (2002), há uma elevação da MO do solo, promovida tanto pelas árvores, via deposição de serrapilheira e decomposição de raízes, com conseqüente aumento da capacidade de troca de cátions, retenção e deposição de nutrientes, redução da perda por erosão e lixiviação dos nutrientes contidos na água da chuva e na poeira atmosférica, que foram interceptados pela copa das árvores; quanto pela deposição de nutrientes pela fauna (animais domésticos).

Alterações na qualidade de pastagens sob sombreamento tem sido bastante documentada, principalmente no que diz respeito a sua composição química (Paciullo et al, 2007; Soares et al, 2009; Oliveira et al, 2005), 
ARAÚJO, R.P. et al. Sistema silvipastoril como alternativa de uso da terra. PUBVET, Londrina, V. 5, N. 38, Ed. 185, Art. 1245, 2011.

justificando a necessidade dos estudo que foram conduzidos e os que ainda irão ocorrer.

No entanto, para evitar efeitos competitivos por luz, água e nutrientes a associação de árvores e pastagem deve ser cautelosa, respeitando suas respectivas fisiologias e exigências nutricionais, buscando manter ou criar um ambiente equilibrado.

\section{SISTEMA SILVIPASTORIL}

Sistema Silvipastoril, é uma modalidade de sistema agroflorestal, que se refere às técnicas de produção nas quais se integram os animais, as árvores e as pastagens numa mesma área. Tais sistemas representam uma forma de uso da terra onde às atividades silviculturais e pecuárias são combinadas para gerar produção de forma complementar pela interação dos seus componentes (Garcia e Couto, 1997).

Com a utilização de espécies adequadas, a arborização das pastagens pode aumentar a produção e qualidade das forrageiras e melhorar o desempenho dos animais em ganho de peso, lactação, sanidade e procriação. Isto se deve à melhoria do microclima para animais domésticos e nativos e também para as plantas, sejam elas forrageiras ou não. Como consequência da implantação de sistemas silvipastoris podem ser citados, ainda, benefícios socioeconômicos (oferta de subprodutos florestais, geração de empregos) e ambientais: captura do gás carbônico, proteção dos recursos hídricos, recuperação de solos degradados, amenização do clima e uma melhoria no equilíbrio ecológico local (Melotto et al., 2007).

Neste cenário de globalização, questões ambientais têm assumido cada vez mais importância social e econômica, e as empresas públicas ou privadas devem estar comprometidas com 0 desenvolvimento ecologicamente sustentado, buscando maior desempenho por adotarem modelos adequados de gestão ambiental, maior lucro e melhor imagem institucional (Schneider, 2005). 
ARAÚJO, R.P. et al. Sistema silvipastoril como alternativa de uso da terra. PUBVET, Londrina, V. 5, N. 38, Ed. 185, Art. 1245, 2011.

Nesse sentido, o sistema silvipastoril tem como objetivo principal permitir maior diversidade e sustentabilidade. Do ponto de vista ecológico, a coexistência de mais de uma espécie em uma mesma área pode ser justificada em termos da ecologia de comunidades, desde que as espécies envolvidas ocupem nichos diferentes, de tal forma que seja mínimo o nível de interferência (Budowski, 1991).

O uso desta técnica se faz necessário pelo fato de nas últimas três décadas, a expansão da atividade pecuária em áreas de floresta tem sido muito expressiva. Nestas áreas, ocorrem à formação de pastagens realizada após a derrubada da mata, queima da biomassa florestal e plantio de forrageiras. No entanto, estas pastagens de primeiro ciclo só produzem satisfatoriamente até o quinto ano, dependendo do sucesso da sua implantação. Há evidências de que a substituição de grandes áreas de floresta para a produção pecuária constitui prática extremamente destrutiva, com consequências desastrosas para a produtividade do solo depois de poucos anos, fato do manejo inadequado das pastagens (Magalhães et al., 2004).

Em contrapartida a esses fatos acima relacionados, os sistemas silvipastoris e agrossilvipastoris apresentam grande potencial de benefícios econômicos e ambientais tanto para os produtores como para a sociedade, por serem sistemas multifuncionais onde existe a possibilidade de intensificar a produção, pelo manejo integrado dos recursos naturais, evitando sua degradação (Porfirio da Silva, 2006).

A importância do sistema silvipastoril também pode ser destacada pelo: aumento da biodiversidade; reposição do componente florestal de forma parcial e ordenada em área de pastagem; produção de sombra e redução da intensidade de calor ou frio, proporcionando um ambiente favorável para os animais; renovação e/ou incremento do ciclo orgânico e de nutrientes, principalmente quando se utiliza espécie fixadora de nitrogênio; oferecimento de suplementação alimentar para os animais pelo uso de árvores forrageiras; fornecimento de madeira, lenha, postes, mourões que podem ser utilizados na propriedade rural e/ou produtos de base florestal com agregação de valor 
ARAÚJO, R.P. et al. Sistema silvipastoril como alternativa de uso da terra. PUBVET, Londrina, V. 5, N. 38, Ed. 185, Art. 1245, 2011.

econômico; diversificação de produtos florestais e pecuários na unidade produtiva; melhoria das propriedades físicas e químicas do solo; obtenção de receita adicional; valorização da propriedade; controle da erosão; aumento do conteúdo de água no solo; oferta de pasto de melhor qualidade no período da seca; aumento da retenção de carbono; melhor aproveitamento da mão-deobra na propriedade; melhoria das condições para fauna e flora; controle do sub-bosque com consequente diminuição de uso de herbicida e incêndios florestais (Garcia et al., 2005).

Sabendo dos benefícios da utilização desse sistema, temos então que nos preocupar com o tipo de arranjo estrutural que será adotado, pois este determinará o sucesso desta prática.

\subsection{CLASSIFICAÇÃO DOS SISTEMAS SILVIPASTORIS}

As pesquisas sobre os sistemas silvipastoris começaram a partir do final da década de setenta em Minas Gerais pela Universidade Federal de Viçosa (Garcia e Andrade, 2001) e na Região Sul pela Embrapa Florestas (Ribaski e Montoya, 2001). Nessas regiões, a grande importância dos empreendimentos florestais favoreceu o desenvolvimento de pesquisas sobre os sistemas silvipastoris com espécies para produção de madeira, notadamente com espécies de Eucalyptus e de Pinus.

Estes sistemas podem ser classificados pelo tipo de arranjo (localização das arvores no espaço físico) e sua finalidade (produção animal, florestais ou ambas) (Franke e Furtado, 2001).

Outra classificação existente, que pode perfeitamente se encaixar na mencionada acima é a descrita por Garcia et al. (2003), em que divide os sistemas silvipastoris em: eventuais, que tem o objetivo principal de usufruir os benefícios possíveis de serem obtidos com a integração de animais aos reflorestamentos, e verdadeiros no qual seu objetivo é desenvolver uma alternativa de uso da terra mais sustentável que os sistemas tradicionais, sob os diferentes pontos de vista. 
ARAÚJO, R.P. et al. Sistema silvipastoril como alternativa de uso da terra. PUBVET, Londrina, V. 5, N. 38, Ed. 185, Art. 1245, 2011.

Tendo em vista essas classificações, podemos relatar os principais arranjos estruturais de um sistema silvipastoril:

- Árvores dispersas ou isoladas na pastagem: Nesta modalidade de arborização de pastagem o objetivo principal é proporcionar proteção ao rebanho, como sombra, quebra-vento, evitando estresse térmico e visando a melhoria da produção dos animais e da qualidade da pastagem (Montoya et al., 1994). Esta normalmente é praticada em pequenas propriedades rurais que utiliza o sistema de derrubada e queima em suas atividades agrícolas. Porém, para que se faça o estabelecimento de árvores isoladas em pastos, dois problemas iniciais, devem ser vencidos: a definição de espécies quando esta não for oriunda de regeneração natural e os métodos de proteção às mudas, pois os animais têm propensão em danificar ou destruir as mudas plantadas em pastos (Baggio e Carpanezzi, 1989).

Este arranjo estrutural é muito difícil de ser adotado pelos produtores, devido à grande dificuldade de implantação em áreas onde já existe a pastagem, pois os gastos com proteção e com a produção de mudas altas são os principais empecilhos. Sua utilização fica facilitada quando os produtores iniciam o processo de renovação de seus pastos (Galvão, 2000).

Neste modelo, as árvores são plantadas em uma distribuição aleatória nas pastagens, sem que haja um espaçamento definido. Geralmente, os objetivos também são proteção do solo, reciclagem de nutrientes, sombreamento para o gado, que proporciona melhoria no bem estar animal, podendo ainda obter produtos tais como madeira, resinas, óleos, etc (Oliveira et al., 2003).

- Bosquestes: Referem-se ao plantio de pequenos grupos de árvores distribuídos na pastagem. Dentro dos bosquetes as árvores, geralmente são estabelecidas em espaçamentos de $3 \times 2 \mathrm{~m}$ e $3 \times 3 \mathrm{~m}$. existindo duas desvantagens desse tipo de arranjo: 1) pouco crescimento do pasto dentro do bosquete, consequência do excessivo sombreamento normalmente observado 
ARAÚJO, R.P. et al. Sistema silvipastoril como alternativa de uso da terra. PUBVET, Londrina, V. 5, N. 38, Ed. 185, Art. 1245, 2011.

nessas condições; 2) desuniformidade na reciclagem de nutrientes no sistema silvipastoril, devido a concentração de deposição de fezes e urina dos animais no interior do bosquete. Com o tempo, há diminuição da fertilidade do solo na área de pasto entre os bosquetes (Oliveira et al., 2003).

O uso de árvores em bosquetes é a forma mais fácil de convencer o pecuarista a estabelecer sombra para seus animais. Sua implantação é fácil e consta dos seguintes passos: vedação da área com cerca, plantio das espécies, desbaste para produção de lenha fina ou outros produtos e liberação da área três a quatros anos após o plantio (Galvão, 2000).

- Árvores em faixas: As árvores são dispostas em espaçamentos regulares entre linhas simples ou faixas com duas linhas e entre plantas na linha de plantio. Geralmente, no arranjo com linhas duplas, as árvores são dispostas em espaçamentos $2 \times 3$ ou $3 \times 3 \mathrm{~m}$, dentro da faixa de plantio (Oliveira et al., 2003). Em área com relevo ondulado as árvores devem ser plantadas em nível, enquanto para terrenos planos deve-se dar preferência para o plantio no sentido leste-oeste, o que permitirá maior incidência de luz no sub-bosque e, consequentemente, melhores condições para crescimento da forrageira na entrelinha.

Já quando a utilização deste sistema tem como foco principal a produção (madeira, celulose, carvão, frutos e forragem) temos:

- Pastejo sob florestas: quando há criações de animais, selvagens ou domésticos em pastagem sob floresta. A utilização de pastagem nativa que crescem sob florestas (Barreto et al., 2006).

- Pastejo sob reflorestamento jovem: quando há criações de animais sob reflorestamentos com pouca idade, em geral até que o sombreamento atue como fator limitante.

- Árvores de valor madeireiro associadas à pastagem: quando há criação de animais em pastagem sob florestas naturais ou plantadas, formadas de espécies que produzem madeira de alto valor comercial. A exemplo temos o 
ARAÚJO, R.P. et al. Sistema silvipastoril como alternativa de uso da terra. PUBVET, Londrina, V. 5, N. 38, Ed. 185, Art. 1245, 2011.

pastejo de bovinos e ovinos em povoamento de Eucalyptus citriodora em pasto de Panicum maximum, no estado de Minas Gerais (Almeida, 1991).

- Árvores frutíferas associadas à pastagem: há criação de animais em pastagens e uma complementação da alimentação, freqüentemente de melhor qualidade, oriunda das árvores. Como exemplo, pastagem de capim búfel (Cenchrus ciliares), com Acácia tortilis, A. nilotica e Albizia celeck, foram sistemas bem sucedidos aplicados na Índia, segundo Deb e Pathak (1983), citados por Macdicken e Vergara (1990).

- Cercas-vivas: neste as árvores atuam como delimitadores de pastos e propriedades. A utilização de eucaliptos bordando os piquetes do sistema silvipastoril como mourões vivos, formando a "eucacerca" (DUBÉ, 1999). Há muitas espécies para serem utilizadas como cerca viva como a algaroba e a leucena.

- Quebra vento: é indicado para regiões onde ocorre vento seco e forte, como no cerrado. As espécies mais utilizadas são o eucalipto, segundo Salmerón (1966) apud Dubé (1999) Casuarina equisetiofilia, Leucaena spp., Dalbergia sisoo, Pinus spp e Acacia spp.

- Árvores para conservação e melhoramento do solo nas pastagens: as modificações nas condições ambientais no solo e na interface solo-liteira de áreas sob a copa de árvores, exercem efeitos positivos sobre as atividades biológica do solo e o aumento na mineralização de $\mathrm{N}$ em pastagens sombreadas em comparação com áreas não sombreadas da pastagem (JOFFRE et al., 1988; HANG et al., 1995, citados por CARVALHO, 1998).

- Árvores para produção de forrageiras para peixes: o plantio de árvores nos taludes de tanques, represas ou açudes têm o objetivo de produzir forragem para peixes e de proteção e estabilização do talude.

- Árvores como Banco de Proteína: Plantio de leguminosas arbustivas ou arbóreas com alta capacidade de fixação de nitrogênio e rebrota, para complementar a dieta dos animais. A leucena (Leucaena leucocephala) e o guandu (Cajanus cajan) são utilizados com esta finalidade. (Costa, 2005). O Banco de proteína é usado em corte ou pastejo direto (Galvão, 2000) por 
ARAÚJO, R.P. et al. Sistema silvipastoril como alternativa de uso da terra. PUBVET, Londrina, V. 5, N. 38, Ed. 185, Art. 1245, 2011.

espécies animais como: bovinos, caprinos ou ovinos. As Leguminosas forrageiras possuem melhor valor nutritivo, em relação às gramíneas tropicais (maior conteúdo de nutrientes e alta digestibilidade), proporcionam um maior consumo de nutrientes digestíveis totais e energia, elevando o desempenho animal, à medida que sua participação na pastagem aumenta (Ulyatt e Mcnabb, 2000). Estes bancos forrageiros são plantios homogêneos, em altas densidades, com espécies de alto valor forrageiro, alta produção de biomassa, e proteína, além de outros produtos de uso na propriedade.

Um dos principais empecilhos à adoção dos sistemas silvipastoris é a combinação entre o arranjo estrutural e a espécie arbórea, pois o sinergismo entre esses dois itens determinará a perpetuação deste ao longo dos anos.

A árvore teoricamente ideal para o sistema silvipastoril teria que ter crescimento inicial relativamente rápido, para facilitar o estabelecimento, copa reduzida ou pouco densa e fuste longo, para diminuir o sombreamento na pastagem, e capacidade de regeneração rápida, quando parcialmente danificada. Economicamente, seria desejável que a árvore oferecesse produtos (madeira, óleo, frutos ou carvão etc.) com alto potencial para comercialização. Outra característica desejável seria a ausência ou o baixo potencial invasivo para evitar a propagação excessiva da árvore na pastagem ou para áreas vizinhas (Dias Filho, 2006).

Outros aspectos que devem ser considerados no momento da escolha das árvores a serem cultivadas são: selecionar as espécies de árvores que estejam adaptadas ao clima e solo da região; fazer a escolha com base no tipo de exploração pretendida; ter conhecimento acerca do valor dos produtos que serão obtidos; as árvores devem apresentar crescimento rápido; optar por árvores com raízes profundas; a copa das árvores deve promover um sombreamento apenas moderado; ter capacidade de prover serviços ambientais e não apresentar efeitos negativos sobre os animais, como toxicidade, ou sobre as pastagens, como alelopatia negativa (Paciullo et al., 2007). 
ARAÚJO, R.P. et al. Sistema silvipastoril como alternativa de uso da terra. PUBVET, Londrina, V. 5, N. 38, Ed. 185, Art. 1245, 2011.

Ainda, Castro e Paciullo (2006) relataram que a escolha do componente arbóreo-arbustivo de um sistema silvipastoril deve ser feita, principalmente, com base no tipo de exploração pretendida, seja ela a produção florestal (madeira, celulose, resinas etc.), a produção animal (leite, carne, lã etc.) ou, ainda, um sistema misto em que se obtenham produtos, comercializáveis ou não, tanto do componente florestal quanto do animal. Os mesmos autores ainda relatam que em explorações não rigidamente especializadas, recomenda-se que o componente arbóreo-arbustivo do sistema silvipastoril seja composto por espécies que atendam diferentes finalidades, como a produção de madeira ou moirões para cerca, a produção de forragem para alimentação do gado e o fornecimento de sombra e biomassa rica em $\mathrm{N}$ e outros nutrientes, para melhorar a fertilidade do solo. As espécies cujo propósito seja fornecer um produto comercializável, madeira ou moirões para cerca, devem ser de crescimento rápido, pois também terão o papel de promover sombra para as espécies arbóreas nativas que por ventura venham a ser introduzidas no sistema, as quais requerem tal condição durante os primeiros anos. Devem-se preferir aquelas bem adaptadas às condições de acidez e baixa fertilidade do solo, como a espécie exótica do gênero Eucalyptus ou Cedro Australiano.

\subsection{COMPONENTE ARBÓREO}

As florestas no mundo somam cerca de 4 bilhões de hectares, cobrindo aproximadamente $30 \%$ da superfície terrestre do globo. Cinco países concentram mais da metade da área florestal total - a Federação Russa 808,8 milhões há; Brasil 477,7 milhões há; Canadá 310,1 milhões há; Estados Unidos 303,1 milhões ha e China 197,3 milhões ha. As florestas tropicais representam $47 \%$ do total, com a maior parte concentrada no Brasil. O eucalipto é a árvore mais plantada no mundo, com mais de 17,8 milhões de hectares, sendo o Brasil o segundo maior país em área plantada, tendo o estado de Minas Gerais como o maior produtor com cerca de um milhão e meio 
ARAÚJO, R.P. et al. Sistema silvipastoril como alternativa de uso da terra. PUBVET, Londrina, V. 5, N. 38, Ed. 185, Art. 1245, 2011.

de hectares (SBS, 2001). No Brasil a eucaliptocultura é intensiva e baseada principalmente em florestas clonais de elevada produtividade média, chegando atingir valores da ordem de 45-60m³/ha/ano (Mora e Garcia, 2000). Estimativas mais conservadoras indicam que o incremento médio anual está em torno de $35 \mathrm{~m}^{3} / \mathrm{ha}$, podendo variar de $30-60 \mathrm{~m}^{3} / \mathrm{ha} / \mathrm{ano}$, dependendo da região, do material genético e dos tratos culturais. A expansão dos plantios nos últimos anos tem suprido a crescente demanda de matéria-prima para a produção de celulose e papel, carvão vegetal, óleos essenciais, madeira sólida para serraria, postes de eletricidade, mourões de cerca e para construção civil entre outras. Existe ainda outra possibilidade de uso das florestas, como para fixação de carbono, visando diminuir a concentração de dióxido de carbono $\left(\mathrm{CO}_{2}\right)$ na atmosfera (Alfenas et al, 2004).

Para a utilização de arvores em pastagens, o principal ponto que deve ser levado em consideração é o espaçamento de plantio. A escolha do espaçamento adequado tem como objetivo proporcionar para cada indivíduo o espaço suficiente para se obter o crescimento máximo. Os espaçamentos utilizados pelas principais empresas reflorestadoras do Brasil têm sido escolhidos, visando possibilitar a mecanização das atividades de implantação, manutenção e exploração dos maciços florestais, por isso tem sido dada preferência aos espaçamentos com, aproximadamente, três metros entrelinhas. Esse arranjo entre plantas busca facilitar a movimentação de máquinas durante a manutenção e exploração do povoamento, com baixo risco de danos às plantas (Botelho, 1998).

O autor acima ainda relata que um dos principais elementos de tomada de decisão é a análise do espaçamento ótimo de plantio, através de estudos de crescimento dos indivíduos em diferentes espaçamentos, pois a densidade de árvores de um povoamento florestal influencia a taxa de crescimento, qualidade da madeira, idade de corte, e consequentemente, os aspectos econômicos do investimento.

Tendo o espaçamento influência tão marcante na produção de madeira e em sua qualidade, os estudos relativos à densidade dos povoamentos tornam- 
ARAÚJO, R.P. et al. Sistema silvipastoril como alternativa de uso da terra. PUBVET, Londrina, V. 5, N. 38, Ed. 185, Art. 1245, 2011.

se necessários e mais justificados, de modo a acompanhar a marcante evolução das técnicas de manejo florestal (Rensi Coelho et al, 1970).

$\mathrm{Na}$ escolha do espaçamento para formação de sistemas silvipastoris, tem que se levar em consideração não só a área útil por árvore visando seu máximo crescimento, mas também a manutenção das espécies que serão associadas. Segundo Soares et al (2009) o nível de radiação que chega ao estrato inferior de um sistema silvipastoril é determinante para o crescimento e desenvolvimento de espécies em sub-bosque, e para que isso ocorra, é comum a prática de desbastes e desrama quando a competição entre árvores se torna prejudicial na produção de madeira.

Quando o estabelecimento de sistemas silvipastoris é planejado, existe a possibilidade de a distribuição espacial das árvores ser feita de modo que se reduza a competição por luz, permitindo maior persistência e eficiência do sistema como um todo (Carvalho, 1997).

O acompanhamento anual da dinâmica de crescimento das árvores fornece subsídios científicos para a análise do potencial de adaptação dessa espécie em uma determinada região. De modo geral, os resultados de pesquisa mostram que o crescimento em diâmetro é uma característica altamente responsiva aos espaçamentos, por esse motivo, tem-se feito esse tipo de avaliação para testar o efeito do espaçamento sobre estas variáveis (Oliveira, 2005).

A mensuração florestal é um importante elemento no manejo da floresta, uma vez que fornece informações precisas, permitindo assim a tomada de decisões adequadas, além de possibilitar o melhor planejamento de suas atividades. As duas variáveis mais utilizadas para a realização de inventários florestais são a altura e o diâmetro, que são usadas para o cálculo da área basal e do volume de madeira existentes em uma floresta (Freitas e Wichert, 1998).

Esse tipo de avaliação já vem sendo usada há muitos anos, como por exemplo, Trevizol Júnior (1985), através do modelo de crescimento proposto 
ARAÚJO, R.P. et al. Sistema silvipastoril como alternativa de uso da terra. PUBVET, Londrina, V. 5, N. 38, Ed. 185, Art. 1245, 2011.

por Clutter (1963), utilizou dados de parcelas permanentes de plantações de eucalipto para estimar sua produção em volume e área.

\subsection{EFEITOS DA ÁRVORE SOBRE OS ANIMAIS}

É do conhecimento geral que a presença do gado pode propiciar rendimentos extras na floresta, não só pela produção de carne, mas também pela manutenção do povoamento e diminuição do risco de incêndios (Gregor, 1973). No entanto, a presença dos animais em sistema silvipastoril não é apenas para obtenção de lucros adicionais, mas também com o objetivo de reduzir os custos de implantação da floresta, com retorno de receita antecipado através do produto animal, num prazo inferior ao do produto florestal (Garcia e Couto, 1992).

As árvores atenuam as temperaturas extremas em pastagens, reduzem o impacto das chuvas e ventos, promovendo conforto e servindo de abrigo para os animais. O conforto proporciona melhor desempenho produtivo e reprodutivo dos animais.

Em regiões quentes, a existência de sombra nas pastagens influencia positivamente os hábitos de pastejo dos animais (Daly, 1984, citado por Carvalho, 1998). Permiti então uma distribuição mais apropriada da ruminação durante o dia e garantindo mais tempo de descanso.

\subsection{EFEITO SOBRE AS FORRAGEIRAS}

Alterações microclimáticas, acarretadas pelo sombreamento, e suas conseqüências nos solos de pastagens, tais como maior disponibilidade de água e incremento na mineralização do $\mathrm{N}$ do solo, devem contribuir para estimular o crescimento de forrageiras sombreadas. (Carvalho, 1998) As raízes profundas das árvores podem interceptar os nutrientes que foram lixiviados das camadas superficiais e se acumularam no subsolo, geralmente fora do 
ARAÚJO, R.P. et al. Sistema silvipastoril como alternativa de uso da terra. PUBVET, Londrina, V. 5, N. 38, Ed. 185, Art. 1245, 2011.

alcance do sistema radicular das culturas agrícolas e/ou pastagens, e retornálos à superfície na forma de serapilheira.

Em pastagens degradas ou em inicio de degradação, a cobertura vegetal deficiente expõe o solo aos efeitos prejudiciais da erosão hídrica e eólica. (Carvalho,1998). Nestas condições as árvores podem ser um importante componente de conservação do solo, e segundo Balieiro et al (2004) principalmente quanto à proteção do solo e disponibilização de nutrientes, pois com raízes mais profundas, parcial ou totalmente ativas no solo, as árvores permitem a estabilização física da massa do solo seja pelo efeito direto de aproximação das partículas, seja por influência indireta da adição de matéria orgânica sobre as propriedades físicas do solo; a ciclagem de nutrientes situados em profundidades maiores no perfil para a superfície do solo; a reserva temporária de nutrientes, imobilizados nas raízes e parte aérea, evitando sua perda por erosão ou mesmo lixiviação; a redistribuição de C e outros nutrientes em profundidade, favorecendo a atividade microbiana e da fauna do solo, com conseqüências benéficas em termos de aeração e permeabilidade e o aumento da capacidade que os sistemas nos quais as árvores são inseridas possuem, de seqüestrar C.

\subsection{MANEJO DO SISTEMA}

Os princípios de manejo são semelhantes aos que regem o manejo dos animais em outros sistemas. Deve-se observar a carga animal, a capacidade de suporte da pastagem e a sua variação ao longo do ano. Observa-se, ainda, a variedade de fonte alimentar, a suplementação alimentar (sal mineral, ração), fornecimento de água, controle de patologias e do hábitat, incluindo as condições microclimáticas e as instalações.

Em geral, são usadas espécies domésticas como bovinos, ovinos, caprinos, suínos, aves, peixes, camarões, abelhas e bicho da seda, podendo ser manejada ainda a fauna silvestre (capivara, queixada, etc.). Cuidados 
ARAÚJO, R.P. et al. Sistema silvipastoril como alternativa de uso da terra. PUBVET, Londrina, V. 5, N. 38, Ed. 185, Art. 1245, 2011.

especiais devem ser tomados quanto à introdução das espécies exóticas de animais no SAF para que não se tornem pragas. (Costa, 2005).

No caso de pastagens, deve-se ter cuidado quanto à compactação do solo. Porém seu efeito só é percebido nas camadas superiores do solo (Almeida, 1991). É preferível o uso de um número maior de piquetes com menor número de animais e menor tempo de permanência (Garcia e Couto, 2005).

A introdução dos animais em SAF'S deve ser feita de acordo com a altura e diâmetro da árvore para que o animal em pastejo não a danifique (Almeida, 1991). O animal em pastejo evita a invasão de plantas e com isso diminui o custo com a limpeza entre linhas e o risco de incêndio nestas áreas (Almeida, 1991). Como também favorece a ciclagem de nutrientes através de fezes e urinas que retornam ao solo (Garcia e Couto, 2005).

\section{CONSIDERAÇÕES SOBRE O EFEITO ECONOMICO E SOCIAL DO USO DE SISTEMAS AGROSILVIPASTORIS}

O Brasil possui um dos maiores remanescentes de florestas nativas no mundo (cerca de 5,1 milhões de quilômetros quadrados), várias representações de zonas climáticas e inúmeros biomas, dentre eles a Amazônia brasileira. Em função disso, detém 20\% das espécies florestais do mundo. Há estimativas de que a biodiversidade brasileira, se explorada adequadamente e em sua totalidade, poderia gerar dois trilhões de dólares por ano, cerca de quatro vezes o nosso Produto Interno Bruto, PIB de 2003. Nossas áreas exploradas com atividades agropecuárias e florestais não atingem seu potencial máximo produtivo. Mesmo assim, as estatísticas econômicas mostram que o agronegócio florestal brasileiro já representa 5\% de nosso PIB, $17 \%$ das exportações do agronegócio e $8 \%$ do total das exportações brasileiras, gerando 1,6 milhões de empregos diretos e 5,6 milhões de indiretos. Isto diz respeito à borracha natural, madeira, celulose, papel e móveis e seria muito mais impactante se fossem incluídas as 
ARAÚJO, R.P. et al. Sistema silvipastoril como alternativa de uso da terra. PUBVET, Londrina, V. 5, N. 38, Ed. 185, Art. 1245, 2011.

atividades ligadas aos demais produtos não-madeireiros, erva-mate, cogumelo, plantas medicinais, agropecuárias, entre outros, e os serviços ambientais (Campanhola, 2005)

O agronegócio florestal brasileiro tem contribuído socialmente e economicamente apesar de ter parte da responsabilidade sobre os danos ambientais decorrentes do mau uso agropecuário e florestal nos diferentes biomas brasileiros, em especial no Cerrado, na Mata Atlântica e na Amazônia.

No mundo, com o aumento da população e do consumo per capita, estima-se um consumo de madeira da ordem de 1,6 bilhão de metros cúbicos/ano, havendo projeções para 2050 (Anuário FAO, 2004) de 2 a 3 bilhões $\mathrm{m}^{3}$ /ano, com um aumento aproximado de 60 milhões $\mathrm{m}^{3} / \mathrm{ano}$. Atender à demanda futura sem degradar as florestas naturais somente poderá ser conseguido se aumentarmos a eficiência e eficácia da produção, da exploração e da conversão da matéria-prima.

Buscando atender a demanda por madeira sem causar perdas ao ambiente, pesquisas têm sido desenvolvidas com espécies de interesse agroflorestal, em especial: pinus, eucalipto, acácia-negra e outras quatrocentas espécies nativas do Brasil. Incluindo pesquisas com áreas de manejo florestal sustentável para exploração de madeiras na Floresta Amazônica e muitos estudos feitos com espécies de usos múltiplos e com sistemas agroflorestais (Campanhola, 2006).

\section{CONSIDERAÇÕES FINAIS}

O Sistema Silvipastoril é uma prática que tem mostrado muitos benefícios tanto para pecuária quanto para atividade madeireira, proporcionando além de retornos satisfatórios a sustentabilidade do sistema de produção. Sendo por isso, recomendada a sua utilização como uma ferramenta na recuperação de áreas em início de degradação ou mesmo áreas consideradas impróprias para agricultura. 
ARAÚJO, R.P. et al. Sistema silvipastoril como alternativa de uso da terra. PUBVET, Londrina, V. 5, N. 38, Ed. 185, Art. 1245, 2011.

O sucesso na utilização dos sistemas silvipastoris está relacionado com o conhecimento dos componentes que irão compor esse sistema. Daí a grande importância da classificação dos sistemas silvipastoris, para assim determinar a escolha dos componentes que estarão relacionados com o ambiente em que serão introduzidos.

\section{REFERÊNCIAS}

Abreu, P. G. Avaliação de coberturas de cabanas de maternidade em Sistema Intensivo de suinos Criados ao ar Livre (SISCAL) no verão. Revista Brasileira de Zootecnia, v.30, n. 6, 2000.

Alfenas, A.C.; Zauza, E.A.V.; Mafia, R.G.; Assis, T. F. Clonagem e doenças do eucalipto. Viçosa: UFV, 442p. 2004.

Almeida, J.C.C. Comportamenbto do Eucalyptus citriodora hooker, em área pastejadas por bovinos e ovinos no vale do rio doce, Minas Gerais. 1991.44 f. Dissertação (Mestrado em Ciência Florestal) - Universidade Federal de Viçosa, Viçosa - MG.

Alvim, M. J.; Botrel, M.A.; Xavier, D. F. As principais espécies de Brachiaria utilizadas no País. Juiz de Fora: Embrapa Gado de Leite (Comunicado Técnico, 22.). 4p. 2002.

Andrade, C.M.S.; Garcia, R.; Couto, L.; Pereira, O.G. Transmissão de luz em sistemas silvipastoris com eucalipto. Revista Árvore, Viçosa, v.26, n.1, p 19-23, 2002.

Anuário FAO de produtos florestais 2004. Disponível em: <ftp://ftp.fao.org/docrep/fao/012/a0434m13/>. Acesso em: 11 out. 2005.

Baggio, A. J.; Carpanezzi, O. B. Resultados preliminares de um estudo sobre arborização de pastagens com mudas de espera. Boletim de Pesquisa Florestal, Colombo, n. 18/19, p.17-22. 1989.

Balieiro, F.C., Franco, A.A., Dias, P.F., Souto, S.M., Campello, E.F.C. Sistemas agrossilvipastoris: a importância das leguminosas arbóreas para as pastagens na região centro-sul. In: 41 a Reunião Anual da Sociedade Brasileira de Zootecnia. 41, Campo Grande, 2004 Anais... Campo Grande, 2004.

Barreto, A.C.; Lima, F.H.S.; Araújo, Q.R.; Feire, F.J. Características químicas e físicas de um solo sob floresta, sistema agroflorestal e pastagem no sul da Bahia. Caatinga, Mossoró, v.19, n.4, p.415-425, 2006.

Boddey, R.M.; Macedo, R.; Tarré, R.M.; Ferreira, E.; Oliveira, O.C. de; Rezende, C. de P.; Cantarutti, R.B.; Pereira, J.M.; Alves, B.J.R.; Urquiaga, S. Nitrogen cycling in Brachiaria pastures: the key to understanding the process of pasture decline. Agriculture, Ecosystems and Environment. v.103, p.389-403, 2004.

Botelho, S. A. Espaçamento. In: Scolforo, J. R. S. Manejo florestal. Lavras: UFLA/FAEPE, p. 381-405, 1998.

Budowski, G. Aplicabilidad de los sistemas agroforestais In: Seminário sobre planejamento de projetos auto-sustentáveis de lenha para américa latina e caribe, 1991, Turrialba. Anais... Turrialba: FAO, v.1 p. 161-7. 1991.

Campanhola, C. A Pesquisa Florestal Brasileira. Disponível em http://www.ambientebrasil.com.br Acesso em: 14 jun 2006. 
Campanhola, C. Inovação tecnológica frente aos desafios do agronegócio. Disponível em: <http://www.agronline.com.br/artigos/artigo.php?id $=196 \& p=2 n=2>$. Acesso em: 15 nov. 2005.

Carvalho, M.M. Utilização de sistemas silvipastoris. In: Favoretto, V.; Rodrigues, L. R. A.; Rodrigues, T. J. D. (Eds.). Ecossistema de pastagens, 3, 1997, Jaboticabal. Anais... Jaboticabal: FCAV/UNESP, p.164-207. 1997.

Carvalho, M.M. Arborização de Pastagens Cultivadas. Documento n64. EMBRAPA, 1998.

Castro, C. R. T.; Paciullo, D.S.C. Boas práticas para a implantação de sistemas silvipastoris. Juiz de Fora: Embrapa Gado de Leite (Comunicado Técnico, 50.). 6p. 2006.

Clutter, J. L. Compatible growth and yield models for lo blolly pine. Forest science, v.9, n.3, p.354-371, 1963.

Costa, N.L.; Townsend, C. R.; Magalhães, J. A.; Paulino, V. T.; Pereira, R.G.A. Utilização de sistemas silvipastoris na Amazônia Ocidental Brasileira. Revista Electrónica de Veterinaria REDVET, v. 7, n. 1, ene. 2006.

Costa, F. Alimentos para criação intensiva. Almanaque Rural, São Paulo, n. 6, p. 23-31, mar. 2005

Da Silva, S.C.; Nascimento JR. Ecofisiologia de plantas forrageiras. In: Pereira, O.G.; Obeid, J. A.; Nascimento Jr., D.; Fonseca, D.M. (Eds.). Simpósio sobre manejo estratégico da pastagem III. Viçosa. 2006. Anais... Viçosa: UFV. p.1-42. 2006.

Dias-Filho, M.B. Sistemas silvipastoris na recuperação de pastagens tropicais degradadas. In: Gonzaga Neto, S.; Costa, R.G.; Pimenta filho, E.C.; Castro, J.M. da C. (Eds.) Simpósio da reunião anual da sociedade brasileira de zootecnia, 43. 2006. João Pessoa, Anais... João Pessoa: UFPB. p. 535-553. 2006.

Dubé, F. Estudos Técnicos e econômicos de Sistemas agroflorestais com Eucalyptus sp. no noroeste do estado de Minas Gerais: o caso da companhia mineira de metais. 1999. 159p. Dissertação (Mestrado em Ciência Florestal) - Universidade Federal de Viçosa, Viçosa - MG

Embrapa, Empresa Brasileira de Pesquisa Agropecuária. Monitoramento registra redução de queimadas na Amazônia Legal em 2005. Via Satélite: Boletim Informativo do CNPM, Campinas, v. 14, n. 01, Janeiro/Fevereiro 2006.

Fagundes, J. L.; DA Fonseca, D. M.; Mistura, C.; Morais, R. V.; Vitor, C. M. T.; Gomide, J. A.; Nascimento Junior, D.; Casagrande, D. R.; DA Costa, L. T. Características morfogênicas e estruturais do capim-braquiária em pastagem adubada com nitrogênio avaliadas nas quatro estações do ano. Revista Brasileira de Zootecnia, v.35, n.1, p.21-29, 2006.

Franke, I. L.; Furtado, S. C. Sistemas silvipastoris: fundamentos e aplicabilidade. Rio Branco: Embrapa Acre (Documentos, 74). 2001.

Freitas, A. G.; Wichert, M.C.P. Comparação entre instrumentos tradicionais de medição de diâmetro e altura com o criterion 400. Instituto de pesquisas e estudos florestais ISSN 0100-3453 (Circular técnica, 7) 1998.

Galvão, A. P. M.. Reflorestamento de propriedades rurais para fins produtivos e ambientais: um guia para ações municipais e regionais. Brasília: Embrapa Comunicação para Transferência de tecnologia; Colombo, PR: Embrapa Florestas, 351p.; 2000.

Garcia, R., Couto, L. Sistemas silvipastoril. In: Gomide J. A. (ed.). Simpósio internacional sobre produção animal em pastejo, Viçosa, 1997. Anais...Viçosa: UFV, p. 447-471. 1997.

Garcia, R.; Andrade, C.M.S. Sistemas silvipastoris na Região Sudeste. In: Carvalho, M.M.; ALVIM, M.J.; Carneiro, J.C. (Ed.) Sistemas agroflorestais pecuários: opções de 
sustentabilidade para áreas tropicais e subtropicais. 2001. Juiz de Fora. Anais... Juiz de Fora: Embrapa Gado de Leite. p. 189-204. 2001.

Garcia, R.; Bernardino, F. S.; Garcez Neto, A. F.; Sistemas silvipastoris. In: Forragicultura e pastagem: temas em evidencias. 2005. Lavras. Anais... Lavras: UFLA, p. 1-65. 2005.

Garcia, R.; Couto, L.; Andrade, C. M. S. de; Tsukamoto Filho, A. de A. Sistemas silvipastoris na região sudeste: a experiência da CMM. In: Embrapa Gado de Corte. (Org.). Sistemas Agroflorestais e Desenvolvimento Sustentável. 2003. Campo Grande. Anais... Campo Grande: Embrapa. 2003.

Gregor, E.W. Integración del pastoreo en Ia agroforesteria tropical. México y SUS Bosques, 12(5):27-34, 1973.

Macdicken,K.G.,Vergara, N.T.,Agroforestry Classification and Management,1990.

Magalhães, J. A.; Costa, N. de L.; Pereira, R.G. A.; townsend, C. R.; Bianchetti, A. Sistemas silvipastoris: alternativa para Amazônia. Bahia Agrícola. v.6, n.3, 2004.

Medrado, M.J.S. Sistemas Agroflorestais: Aspectos Básicos e Indicações. In: Galvão, A.P.M. Reflorestamento de propriedades rurais para fins produtivos e ambientais. Brasília, 2000, p. $269-312$

Melotto, A.; Bocchese, R.; Scheleder, D. D.; Laura, V. A.; Nicodemo, M. L.; Gontijo Neto, M. M.; Pott, A.; Da Silva, V. P. Crescimento Inicial de Mudas de Espécies Florestais Nativas do Brasil Central Plantadas em Pastagem de Brachiaria brizantha cv. Marandu. Revista Brasileira de Biociências, v. 5, supl. 1, p. 288-290. 2007.

Montoya, L.J.; Medrado, M.J.S.; Maschio, L.M.A. Aspectos de arborização de pastagens e de viabilidade técnica-econômica da alternativa silvipastoril. In: Congresso brasileiro de sistemas agroflorestais, 1. 1994, Porto Velho. Anais... Colombo: Embrapa-CNPF (Documentos, 27). p. 157-171. 1994.

Mora, A.L.E Garcia, C.H. A cultura do eucalipto no Brasil. São Paulo, SBS, 112p. 2000.

Oliveira Neto, S. N.; Reis, G. G.; Reis, M. das G. F.; Neves J.C.L. Produção e distribuição de biomassa em eucalyptus camaldulensis dehn. em resposta à adubação e ao espaçamento. Revista Árvore, v.27, n.1, p.15-23, 2003.

Oliveira, T. K. Sistema agrossilvipastoril com eucalipto e braquiária sob diferentes arranjos estruturais em área de Cerrado. 2005. 150 p. Tese (Doutorado) Universidade Federal de Lavras, Lavras, 2005.

Oliveira, T.K.; Furtado, S.C.; Andrade, C.M.S.; Franke, I.L. Sugestões para implantação de sistemas silvipastoris. Rio Branco, AC: Embrapa Acre. (Documentos, 84). 2003.

Paciullo, D.S.C.; Carvalho, C.A.B.; Aroeira, L.J.M.; Morenz, M. J. F.; Lopes, F.C F.; Rossiello, R.O.P. Morfofisiologia e valor nutritivo do capim-braquiária sob sombreamento natural e a sol pleno. Pesquisa Agropecuária Brasileira, v.42, n.4, p.573-579. 2007.

Paciullo, D.S.C.; Heinemann, A.B.; MACEDO, R. O. Sistemas de produção de leite baseados no uso de pastagens. Revista Eletrônica Faculdade Montes Belos, v.1, n.1., p. 88-106. 2005.

Paciullo, D.S.C.; Porfírio da Silva, V.; Carvalho, M.M.; Castro, C.R.T. Arranjos e modelos de sistemas silvipastoris. In: II simpósio internacional de sistemas agrossilvipastoris na américa do sul. 2007. Juiz de Fora. Anais... Juiz de Fora: Embrapa Gado de Leite. CD ROM. 2007.

Porfírio da Silva, V. Introdução de árvores madeiráveis em pastagens: algumas considerações e procedimentos mínimos. In: Workshop sobre potencial dos sistemas silvipastoris no desenvolvimento de modelos sustentáveis de exploração pecuária. 2006. Juiz de Fora. Anais... Juiz de Fora: Embrapa Gado de Leite. CD ROM. 2006. 
Rensi Coelho, A.S.; Mello, H.A.; Simões, J.W. Comportamento de Espécies de Eucaliptos Face ao Espaçamento. IPEF. n.1. p.29-55. 1970.

Ribaski, J.; Montoya, L. J. Sistemas silvipastoris desenvolvidos na Região Sul do Brasil: a experiência da Embrapa Florestas. In: Carvalho, M.M.; Alvim, M.J.; Carneiro, J.C. (Ed.) Sistemas agroflorestais pecuários: opções de sustentabilidade para áreas tropicais e subtropicais. 2001. Juiz de Fora. Anais... Juiz de Fora: Embrapa Gado de Leite. p. 205233. 2001.

Sánchez, S.; Hernández, M.; Simón, L. Efecto del sistema silvopastoril en la fertilidad edáfica en unidades lecheras de la empresa Nazareno. Pastos y Forrajes, v.26. p.131-136. 2003.

SBS. Sociedade Brasileira de Silvicultura. Disponível em: http://www.sbs.org.br/estatisticas.htm em 21 de agosto de 2009.

Schneider, P.R.; Finger, C.A.G.; Giacomelli Sobrinho, V. et al.. Determinação indireta do estoque de biomassa e carbono em povoamentos de acácia-negra (acacia mearnsii de wild.). Ciência Florestal, v. 15, n. 4, p. 391-402, 2005.

Soares, AB.; Sartor, L. R.; Adami, P.F.; Varella, A.C.; Fonseca, L.; Mezzalira, J.C. Influência da Luminosidade no Comportamento de Onze Espécies. Forrageiras Perenes de Verão. Revista Brasileira de Zootecnia, v.38, n.3, p.443-451, 2009.

Spera, S.T.; Tósto, S.G. ;Macedo, M.C.M. Práticas de conservação de solos sob pastagens para Mato Grosso do Sul. Campo Grande: EMBRAPA-CNPGC (Documentos, 54). 96p. 1993.

Trevizol Júnior, T.L. Análise de um modelo compatível de crescimento e produção em plantações de Eucalyptus grandis (W. Hill ex- Maiden). 1985. 74p. Dissertação (Mestrado e Ciência Florestal) - Universidade Federal de Viçosa, Viçosa - MG

Ulyatt, M.J,; McNabb, W.C. Can Protein Utilisation from pasture be improved. In: Reunião Annual da Sociedade Brasileira de Zootecnia, 36, Porto Alegre - RS, 1999. Anais... Porto Alegre: Sociedade Brasileira de Zootecnia, 1999. 